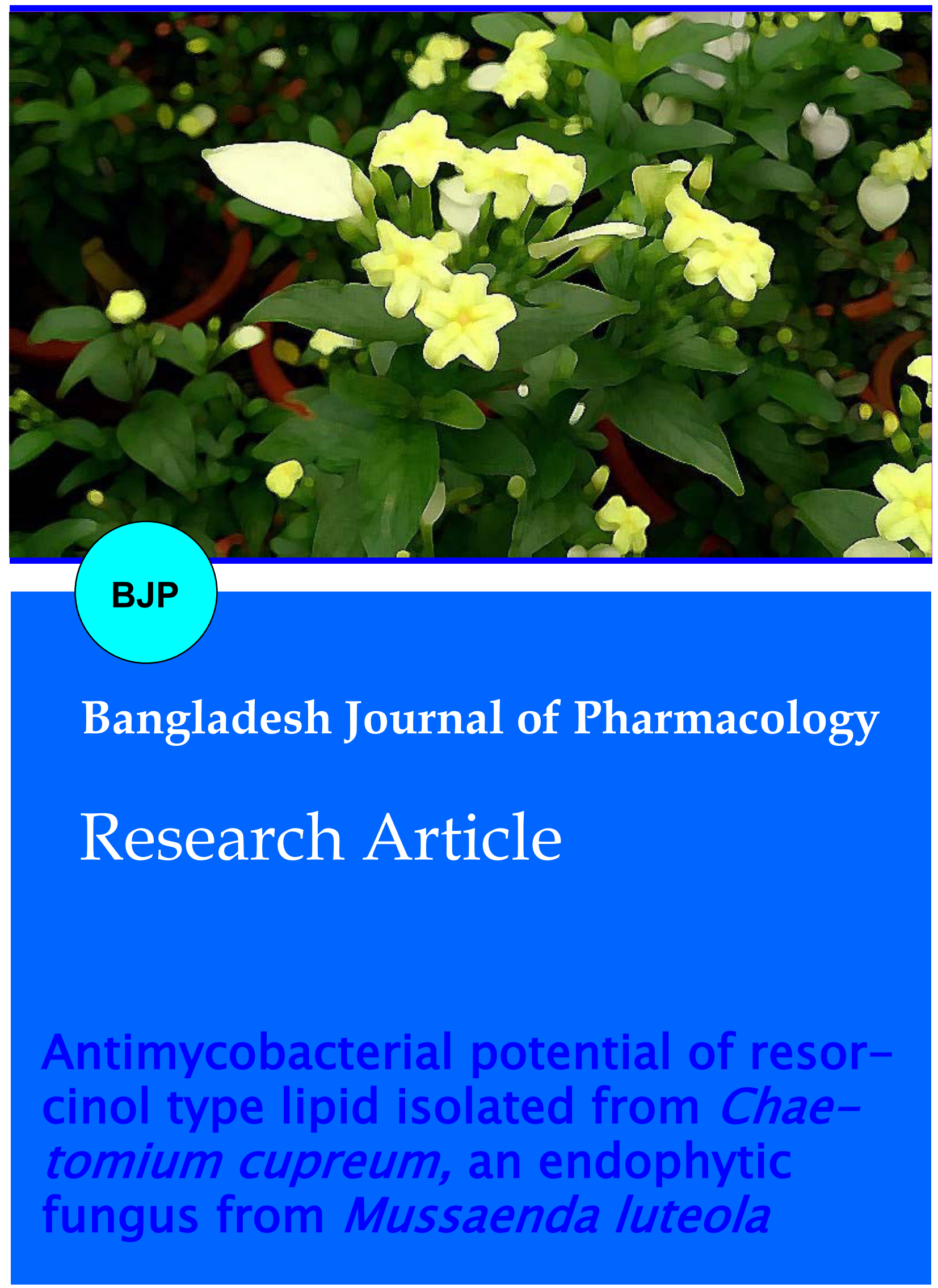


Abstracted/indexed in Academic Search Complete, Asia Journals Online, Bangladesh Journals Online, Biological Abstracts, BIOSIS Previews, CAB Abstracts, Current Abstracts, Directory of Open Access Journals, EMBASE/Excerpta Medica, Google Scholar, HINARI (WHO), International Pharmaceutical Abstracts, Open J-gate, Science Citation Index Expanded, SCOPUS and Social Sciences Citation Index;

ISSN: $1991-0088$

\title{
Antimycobacterial potential of resorcinol type lipid isolated from Chaetomium cupreum, an endophytic fungus from Mussaenda Iuteola
}

\author{
Gunasekaran Shylaja, Kandasamy Sasikumar and Arunachalam Sathiavelu
}

School of Biosciences and Technology, VIT University, Vellore 14, Tamilnadu, India.

\begin{tabular}{lr}
\hline Article Info & \\
\hline Received: & 8 December 2018 \\
Accepted: & 26 March 2018 \\
Available Online: & 5 April 2018 \\
DOI: 10.3329/bjp.v13i2.34860 & \\
& \\
& \\
& \\
Cite this article: & \\
Shylaja G, Sasikumar K, Sathiavelu A. \\
Antimycobacterial potential of resor- \\
cinol type lipid isolated from Chaeto- \\
mium cupreum, an endophytic fungus \\
from Mussaenda luteola. Bangladesh J \\
Pharmacol. 2018; 13: 000-00.
\end{tabular}

\begin{abstract}
An endophytic fungus Chaetomium cupreum was isolated from the ornamental plant Mussaenda luteola. A known metabolite named resorcinol type of lipid (compound 1) was isolated using column chromatography and structurally elucidated by spectroscopic studies includes UV-Vis, FT-IR, NMR, MS analysis and comparing with the existing data. The compound 1 was evaluated for antimycobacterial potential by microtitre plate alamar blue assay against Mycobacterium tuberculosis $\mathrm{H} 37 \mathrm{Rv}$ (ATCC27294). It also estimated for DPPH free radical scavenging and antibacterial (agar well diffusion method) potentials. Compound 1 revealed to have significant inhibition of Mycobacterium with MIC of $6.3 \mu \mathrm{g} / \mathrm{mL}$ which is similar to the standard streptomycin drug. It also exhibited good DPPH free radical scavenging potential of $84.5 \pm 0.4 \%$ and maximum inhibition of both E. coli (ATCC 25922) as well as $S$. aureus (ATCC 25923). Thus, endophytic fungus C. cupreum from Mussaenda luteola could be a potential source of novel lead antimicrobial agents for drug discovery.
\end{abstract}

\section{Introduction}

Medicinal plants, animals, microbes and marine organisms have historically proven their value as a source of bioactive molecules with therapeutic potentials and played a key role in medicinal chemistry to treat human diseases (Cragg and Newman, 2013).

Endophytes can be found in almost all plants and play a vital role in the growth of host plants against stressed condition (Li et al., 2013; Yu et al., 2017). Endophytes have the major impact on drug discovery (Awad et al., 2014) since it proved to be a valuable source of novel and structurally diverse secondary metabolites which may possess various biological potentials such as antimicrobial (Shen et al., 2012; Zhang et al., 2012; Zhang et al., 2015), anti-cancer (Shylaja and Sathiavelu 2017), immunosuppressant and others (Zhang et al., 2014;
Strobel et al., 2005).

The genus Chaetomium is the prevalent group of saprophytic ascomycetes, commonly found in air, soil and plants. The bioactive secondary metabolites chaetoglobosins, chaetoviridins, cytoglobosins, pyrones, orsellides, cytochalasans, anthraquinone, chromanone were reported from Chaetomium spp. New azaphilones like rotiorinols, rotiorin and epi-isochromophilone had been isolated from the C. cupreum (Kanokmedhakul et al., 2006).

Mussaenda luteola is a vital source of bioactive compounds, predominantly iridoids, rutin, quercetin, gallic acid and triterpenes with pharmacological potentials such as cytotoxicity, anti-inflammatory, antipyretic, diuretic, anti-oxidant, antimicrobial and many others (Vidyalakshmi et al., 2008). The present study focussing 


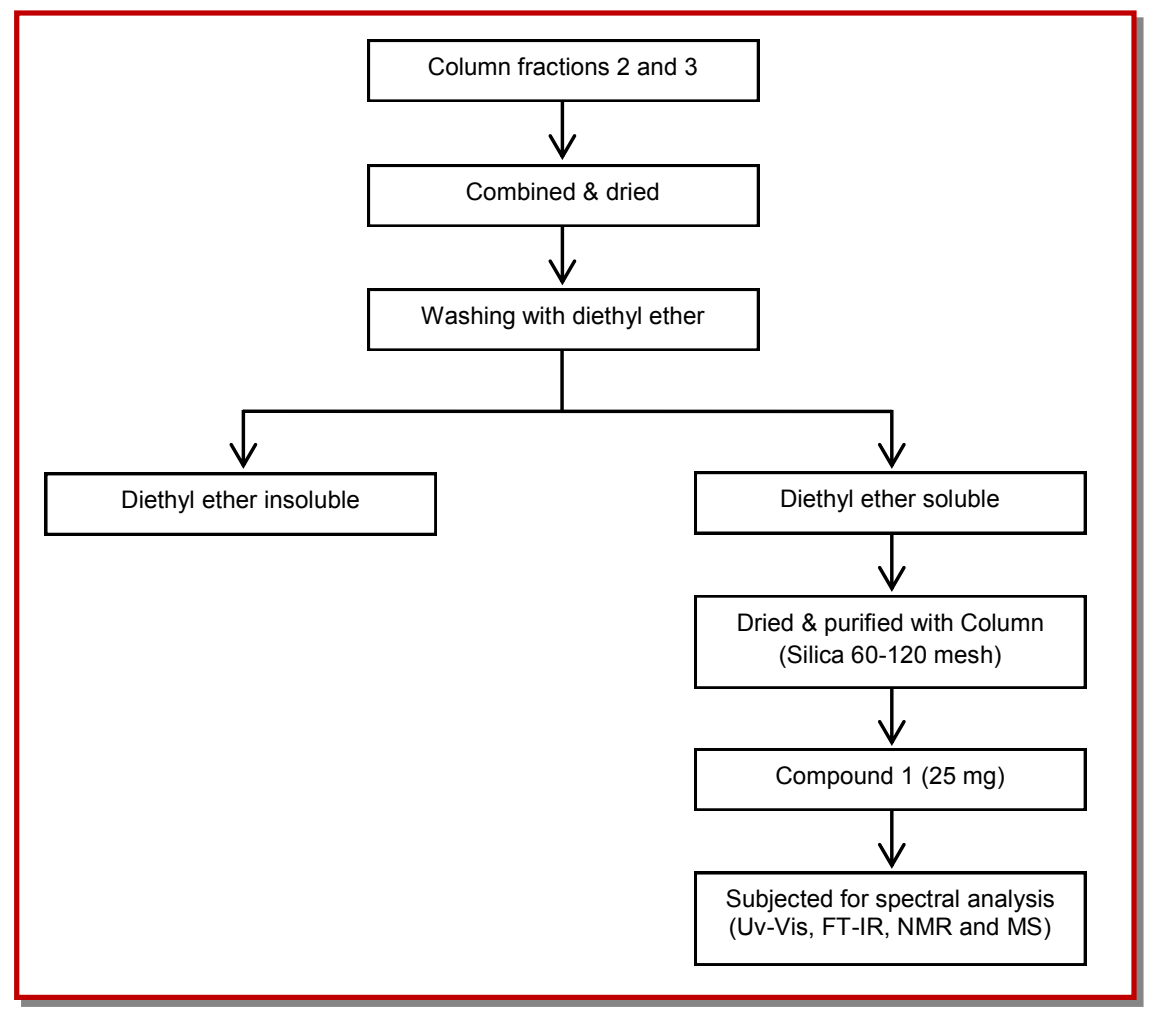

Figure 1: Flow chart for isolation of compound 1 from ethyl acetate extract of C. cupreum

on the isolation and identification of bioactive metabolite of the endophytic fungus C. cupreum from $M$. luteola and to evaluate the anti-oxidant, antibacterial and antimycobacterial potentials.

\section{Materials and Methods}

\section{General experiments}

The isolated compound was determined for maximum wavelength, $\lambda \max$ using UV-Vis spectrophotometer (Shimadzu UV-2401) range between 200-800 nm. FT-IR spectrum analysis was performed in $\mathrm{KBr}$ pellets on a (Shimadzu, FT-IR 8300) between 4000 and $400 \mathrm{~cm}^{-1}$. NMR spectroscopic analysis of the sample was done for ${ }^{1} \mathrm{H}$ NMR (400 MHz) and ${ }^{13} \mathrm{C}$ NMR (100 MHz) using Bruker Avance 400 NMR spectrometer. The chemical shifts were reported in parts per million relative to tetramethylsilane in deuterated chloroform $\left(\mathrm{CH}_{\mathrm{d}} \mathrm{Cl}_{3}\right)$ as a solvent

\section{Isolation, cultivation, and extraction of the fungal strain.}

The fungus used in this study was isolated from the leaves of M. luteola (Schulz et al., 1993) and identified as C. cupreum on the basis of the rDNA internal transcribed spacer gene sequence. Seven-days grown colonies of the C. cupreum on PDA plate were cut into small pieces and dropped in $1 \mathrm{~L}$ flask contained $400 \mathrm{~mL}$ of potato dextrose broth for fermentation and kept for incubation at $25^{\circ} \mathrm{C}$ for three weeks (Arivudainambi et al., 2011). The fermented fungal broth was filtered to remove fungal mycelium.

\section{Extraction and metabolite isolation}

The fungal filtrate was extracted with ethyl acetate and concentrated under vacuum. The obtained dried extract was fractionated by silica gel (60-120 mesh) column chromatography (Chang et al., 2017) using chloroform/ methanol (100:00, 80:20, 60:40, 40:60, 20:80 and 0:100) gradient elution to provide 18 fractions. The fractions were determined for maximum wavelength, $\lambda$ max using UV-Vis spectrophotometer. Fraction 2 and 3 showed the maximum wavelength of $502 \lambda_{\max }$ and also similar thin layer chromatography profile. So, these fractions were combined and further purified by column over silica gel (60-120 mesh) using isocratic elution with diethyl ether (Figure 1). The solvent was removed under reduced pressure which afforded compound 1 ( $25 \mathrm{mg}$ ).

\section{DPPH radical scavenging assay}

Free radical scavenging potential of compound 1 from endophytic fungus was determined using $\mathrm{DPPH}$ method (Yadav et al., 2014). The absorbance was measured at $517 \mathrm{~nm}$ and ascorbic acid was used as reference compound. Each analysis was done in triplicate. 


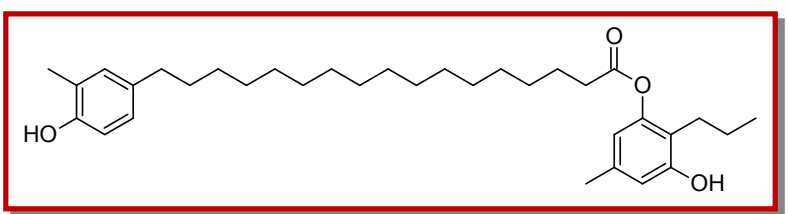

Figure 2: Structure of resorcinol type lipid isolated from C.cupreum

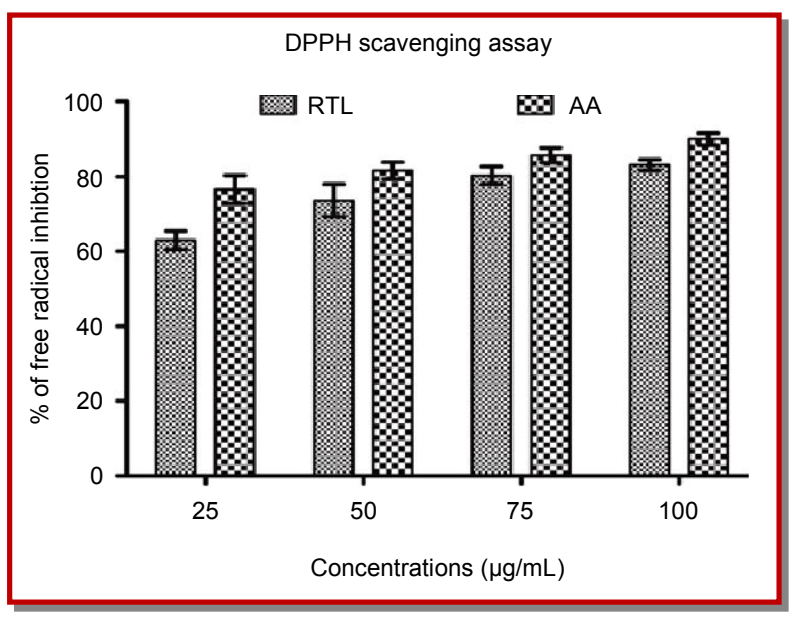

Figure 3: DPPH free radical scavenging activity of resorcinol type lipid isolated from C. cupreum

Note: RTL- Resorcinol Type Lipid; AA- Ascorbic acid

\section{Antibacterial assay}

The antibacterial efficacy of compound 1 was determined by agar-well diffusion method (Ahmad and Beg, 2001) against bacterial strains Gram positive, Staphylococcus aureus (ATCC 25923) and Gram negative Escherichia coli (ATCC 25922). The compound 1 was dissolved in dimethyl sulfoxide $(1 \mathrm{mg} / \mathrm{mL})$ and prepared four concentration range from $0.500,0.250,0.125$ and 0.061 $\mathrm{mg} / \mathrm{mL} .40 \mu \mathrm{L}$ of each concentration was added to wells $(6 \mathrm{~mm})$ made from the MHA plates. The plates were kept for overnight incubation at $37^{\circ} \mathrm{C}$.

\section{Determination of in vitro antimycobacterial activity against $M$. tuberculosis $\mathrm{H} 37 \mathrm{Rv}$}

The antimycobacterial potential of compound 1 was assessed based on the microplate alamar Blue assay (MABA) (Collins and Franzblau, 1997) against Mycobacterium tuberculosis H37Rv (ATCC27294). Briefly, the stock solution of compound 1 was prepared in dimethyl sulfoxide and added $100 \mu \mathrm{g} / \mathrm{mL}$ concentration to the well of a microplate containing Middlebrook 7H12 broth (Falzari et al., 2005) and 2-fold serial dilutions were done in 7H12 media to yield a final concentrations ranging from 100 to $0.2 \mu \mathrm{g} / \mathrm{mL}$. $40 \mu \mathrm{L}$ M. tuberculosis H37Rv culture $(3 \times 105 \mathrm{CFU} / \mathrm{mL})$ was added to all wells except media control well. Pyrazinamide, ciprofloxacin and streptomycin were used as standard controls. Then Mycobacteria plus dimethyl sulfoxide and media alone used as a negative control. The microplate was sealed and incubated for 6 days at $37^{\circ} \mathrm{C}$. After incubation, $25 \mu \mathrm{L}$ of alamar blue reagent was added to all wells and re-incubated for 24 hours at $37^{\circ} \mathrm{C}$. The color change from blue to pink indicated the reduction of resazurin due to bacterial growth. The lowest concentration in which the drug is preventing the color change was determined as minimum inhibitory concentration.

\section{Results}

The endophytic fungus C. cupreum was isolated from the leaves of M. luteola. The fungus was identified based on morphological and molecular studies (GenBank ID: KY806554). A crude ethyl acetate extract of C. cupreum was subjected to silica gel column to yield resorcinol type lipid.

\section{Resorcinol type lipid (1)}

Yellowish orange powder; The molecular ion peak at $\mathrm{m} / \mathrm{z} 526.8306[\mathrm{M}+\mathrm{H}]+$ by HRESIMS indicated the molecular formula of $\mathbf{1}$ was $\mathrm{C}_{34} \mathrm{H}_{52} \mathrm{O}_{4}$ (Calcd. $524.786 \mathrm{~g}$ / mol); UV -Vis $\left(\mathrm{CHCl}_{3}\right) \lambda \max (\log \epsilon)$ 502, 295 and 208 nm; FT-IR (KBr) $\mathrm{V}_{\max }$ signal bands were 3298, 2960, 2873, 1722, 1612, 1450, 1368, 1201, 1045, 947, 879, 790, $731,574,482 \mathrm{~cm}^{1} .{ }^{1} \mathrm{H} \mathrm{NMR}\left(\mathrm{CDCl}_{3}\right)$ spectrum represent the peaks corresponding to chemical shifts (52 protons) at ppm $\delta 4.18(1 \mathrm{H}, \mathrm{t}, \mathrm{H}-2), \delta 4.16(1 \mathrm{H}, \mathrm{t}, \mathrm{H}-5), \delta 4.15(1 \mathrm{H}$, t, H-6), $\delta 4.14(1 \mathrm{H}, \mathrm{t}, \mathrm{H}-27), \delta 4.15(1 \mathrm{H}, \mathrm{t}, \mathrm{H}-29), \delta 7.51$ $(1 \mathrm{H}, \mathrm{t}, \mathrm{C}-4 \mathrm{OH}), \delta 7.53(1 \mathrm{H}, \mathrm{t}, \mathrm{H}-26), \delta 0.83(3 \mathrm{H}, \mathrm{s}, \mathrm{H}-$

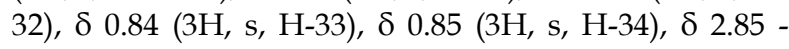
$2.328(2 \mathrm{H}, \mathrm{m}, \mathrm{H}-7$ to $\mathrm{H}-22), \delta 2.31(2 \mathrm{H}, \mathrm{m}, \mathrm{H}-30)$ and $\delta$ $2.311(2 \mathrm{H}, \mathrm{t}, \mathrm{H}-31) .{ }^{13} \mathrm{C} \mathrm{NMR}\left(\mathrm{CDCl}_{3}\right)$ spectrum represent the peaks corresponding to chemical shifts (34 carbon) at ppm $\delta 129.69$ (C-1), $\delta 114.07$ (C-2), $\delta 129.69$ (C-3), $\delta$

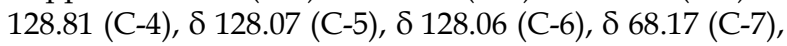

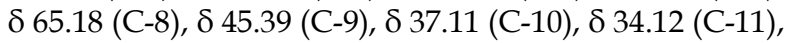

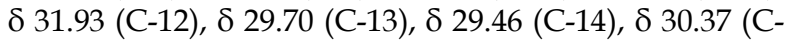

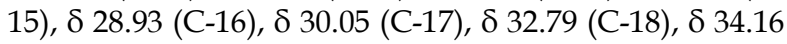
(C-19), $\delta 38.74$ (C-20), $\delta 65.05$ (C-21), $\delta 70.28$ (C-22), $\delta$

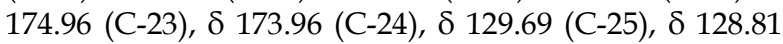

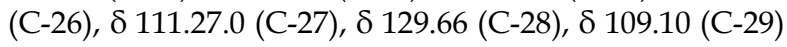
and $\delta 68.40$ (C-30), $\delta 24.48$ (C-31), $\delta 20.54$ (C-32), $\delta 23.75$ (C-33) and $\delta 22.70$ (C-34). The FT-IR, NMR and MS data obtained from compound 1 (Figure 2) were identical to the published data of resorcinol type of lipid (2-propyl3-hydroxy-5-methyl phenyl 17-(3-methyl-4-hydroxy phenyl) heptadecane ester) (Venil et al., 2014).

\section{Anti-oxidant assay}

The isolated compound showed significant DPPH scavenging potential of $84.5 \pm 0.4 \%$ compared to the standard ascorbic acid $(89.9 \pm 0.1 \%)$ at a concentration of $100 \mu \mathrm{g} / \mathrm{mL}$. The percentage inhibition of DPPH and ascorbic acid are shown in Figure 3. 


\begin{tabular}{|c|c|c|}
\hline \multicolumn{3}{|c|}{ Table I } \\
\hline \multicolumn{3}{|c|}{$\begin{array}{l}\text { Antimicrobial potential of resorcinol type } \\
\text { lipid isolated from } C \text {. cupreum }\end{array}$} \\
\hline \multirow[t]{2}{*}{ Dose $(\mu \mathrm{g}) /$ well } & \multicolumn{2}{|c|}{ Zone of inhibition (mm) } \\
\hline & E.coli & S. aureus \\
\hline 05 & 10 & 10 \\
\hline 10 & 11 & 12 \\
\hline 20 & 12 & 13 \\
\hline 40 & 14 & 14 \\
\hline
\end{tabular}

Table II

Antimycobacterial activity of $C$. cupreum against Mycobacterium tuberculosis H37Rv

\begin{tabular}{|lcc|c|c|}
\hline Strain & \multicolumn{4}{c|}{$\begin{array}{c}\text { Minimum inhibition concentration } \\
(\mu \mathrm{g} / \mathrm{mL})\end{array}$} \\
\hline Strain & RTL & PZA & CIP & STM \\
M. tuberculosis $\mathrm{H}_{37} \mathrm{R}_{\mathrm{V}}$ & 6.3 & 3.1 & 3.1 & 6.3
\end{tabular}

RTL: Resorcinol type lipid; PZA: Pyrazinamide; CIP: Ciprofloxacin; STM: Streptomycin

\section{Antibacterial assay}

The compound 1 exhibited strong inhibition against both test pathogens of Gram positive $S$. aureus and Gram negative E. coli with the zone of inhibition of 14 $\mathrm{mm}$ at the concentration of $40 \mu \mathrm{g} / \mathrm{mL}$ (Table I).

\section{Antitubercular assays}

Results for the investigation of isolated resorcinol type lipid (1) against $M$. tuberculosis H37Rv are presented in Table II. It was observed that compound 1 possess significant inhibition of Mycobacterium with MIC 6.3 $\mu \mathrm{g} / \mathrm{mL}$ which was similar to the standard streptomycin.

\section{Discussion}

The genus Mussaenda is an ornamental plant with many pharmacologically active phytochemicals (Gunasekaran et al., 2015). The compound resorcinol type lipid was isolated from ethyl acetate extract of C. cupreum by column chromatography. Resorcinolic lipids have been extensively found in both plants and microorganisms. It possesses many biological applications with the characteristic of 1, 3-dihydroxybenzene core with saturated chains at 5-position of the aromatic ring (Nagy et al., 1998).

The Infrared (IR) of compound 1 showed a peak at 3298 $\mathrm{cm}^{-1}$ which may be due to the presence of hydroxyl group, while the peak at 1722 and $1612 \mathrm{~cm}^{-1}$ may be due to the presence of carbonyl group (C-O). These two peaks may likely be due to the presence of carboxylic acid functional group or ester $(\mathrm{COOH})$. The shifts in carbonyl and the hydroxyl absorption spectra of the pigment can be related to strong chelation (Nagy et al., 1998; Deveoglu et al., 2012). The peak at $1368 \mathrm{~cm}^{-1}$ may be due to the presence of tri-substituted olefinic group, while the peak at $1201 \mathrm{~cm}^{-1}$ may be due to the presence of - $\mathrm{CH} 3$ and -CH2- signals. The peak at 2960 and 2873 $\mathrm{cm}^{-1}$ may be due to the presence of $\mathrm{C}-\mathrm{H}$ stretch for alkanes. This signal suggests that the molecule may be highly saturated. Also, the absorption bands at 947 to $482 \mathrm{~cm}^{-1}$ are due to asymmetric C-H stretching in alkyl hydrocarbons which corresponds to the resorcinol type lipid (flexirubin class of pigment) (Bej, 2011).

The ${ }^{1} \mathrm{H}-\mathrm{NMR}$ spectrum of compound 1 showed three singlets methyl groups at $\delta 0.85,0.84$, and $0.83(\mathrm{H}-32$, 33 , and 34). The olefinic proton at C-2, C-5, C-6, C-27 and C-29 appeared at $\delta 4.18,4.16,4.15,4.14$ and 4.152 as a triplet $(\mathrm{J}=3.5 \mathrm{~Hz})$ respectively. A one proton double doublet at $\delta 2.85$ was assigned to $\mathrm{H}-18$ on the basis of its chemical shift as well as multiplicity pattern reported for $\mathrm{H}-18$ with $\beta$-stereochemistry.

${ }^{13} \mathrm{C}-\mathrm{NMR}$ spectrum of compound 1 exhibited thirty-four carbon peaks. The peak at $\delta 174.37$ may be due to the presence of carbonyl group assigned to C-23. The two peaks at $\delta 129.69,114.07,111.27,109.10,128.81,128.07$, and 128.06 may be due to the presence of a pair of sp2 hybridized carbon atoms assigned in two benzene ring between $\mathrm{C} 1$ to $\mathrm{C} 6$ and C-24 to C-29. While the seven peaks at $\delta 22.70,23.75$ and 20.54 are attributable to the three methyl groups which are assigned to C-32, C-33 and C-34 respectively. Therefore, compound 1 could be assigned as 2-propyl-3-hydroxy-5-methyl phenyl 17-(4hydroxy-3-methyl phenyl) heptadecane (Resorcinol type lipid).

The isolated compound 1 found to be a resorcinol type lipid contain chromophores of phenyl octaenic acid esterified with resorcinol carrying three hydroxyl group and one hydrocarbon chains (1,4,5 trihydroxy -3-propyl benzene). The chemical structure of compound 1 is characterized by non-isoprenoid phenyl-substituted poly alkane carboxylic acid (Reichenbach and Kleinig, 1974). This basic chemical structure of resorcinol type lipid may be modified length variation and branching of the hydrocarbon chains on the resorcinol. In this way, a large diversity of different resorcinol type lipid arises along with changes in physical properties (Stafsnes and Bruheim, 2013).

Free radicals, a major responsible for many chronic diseases, due to toxicity and many health threats the synthetic anti-oxidants can be replaced by natural sources (Wong et al., 2006). Pestacin and iso-pestacin major anti-oxidant agents isolated from endophyte Pestalotiopsis microspore of the plant Terminalia morobensis (Guo et al., 2008). DPPH free radical scavenging assay is the most precise and extensively used assay for 
determining anti-oxidant activity (Yadav et al., 2014). In this study, the isolated compound had inhibition of DPPH similar to the ascorbic acid.

Chaetoglobosins $\mathrm{A}$ and $\mathrm{C}$ were reported from the endophytic fungus C. globosum of the plant Ginkgo biloba was found to have antibacterial property against Mucor miehei. A novel peptide cryptocandin from Cryptosporiopsis quercina revealed antibacterial activity against C. albicans and also many other compounds had been identified from endophytic fungus as antimicrobials (Yu et al., 2010).

Tuberculosis is a deadly and transmittable disease caused by $M$. tuberculosis. More than 8.8 million new cases and 1.5 million deaths were accounted worldwide in 2010 as indicated by the most recent WHO report (Alvin et al., 2014). Tuberculosis was stated to be a global health emergency because of the high incident in HIV co-infection and the existence of multidrugresistant (MDR) and extensively drug-resistant strains (XDR-TB) (Lienhardt et al., 2012). New anti-mycobacterial entities with unique mechanisms of action are therapeutically needed for treating resistant forms of tuberculosis. Endophytes an alternate source of novel antimycobacterial compounds. Penialidin C and citromycetin from the endophytic fungus Penicillium sp. were found to be most effective in inhibition of Mycobacterium sp. with MIC of 15.6 and $31.2 \mu \mathrm{g} / \mathrm{mL}$ respectively (Jouda et al., 2016).

\section{Conclusion}

The compound resorcinol type lipid isolated from the endophytic fungus C. cupreum has a significant antimycobacterial and anti-oxidant properties. It can be used as a lead molecule for drug development process.

\section{Conflict of Interest}

Authors declare there is no conflict of interest.

\section{Acknowledgement}

The authors acknowledge to the VIT University, India for laboratory facility and their support.

\section{References}

Ahmad I, Beg AZ. Antimicrobial and phytochemical studies on 45 Indian medicinal plants against multi-drug resistant human pathogens. J Ethnopharmacol. 2001; 74: 113-23.

Alvin A, Miller KI, Neilan BA. Exploring the potential of endophytes from medicinal plants as sources of antimycobacterial compounds. Microbiol Res. 2014; 169: 483-95.
Arivudainambi US, Anand TD, Shanmugaiah V, Karunakaran C, Rajendran A. Novel bioactive metabolites producing endophytic fungus Colletotrichum gloeosporioides against multidrug-resistant Staphylococcus aureus. FEMS Immunol Med Microbiol. 2011; 61: 340-45.

Awad NE, Kassem HA, Hamed MA, El-Naggar MA, El-Feky AM. Bioassays guided isolation of compounds from Chaetomium globosum. J Mycol Med. 2014; 24: e35-42.

Bej AK. Anti-cancer and antimicrobial compounds from Antarctic extremophilic microorganisms. 2011. Patent No. 20110301216.

Chang CI, Wang SY, Wu MD, Cheng MJ, Ko HH, Chang HS, Chen JJ, Chen CC, Kuo YH. Two new sesquarterpenoids from the bark of Cryptomeria japonica. Phytochem Lett. 2017; 22: 56-60.

Collins LA, Franzblau SG. Microplate alamar blue assay versus BACTEC 460 system for high-throughput screening of compounds against Mycobacterium tuberculosis and Mycobacterium avium. Antimicrob Agents Chemother. 1997; 41: 100409.

Cragg GM, Newman DJ. Natural products: A continuing source of novel drug leads. Biochem Biophys Acta. 2013; 1830: 3670-95.

Deveoglu O, Cakmakci E, Taskopru T, Torgan E, Karadag R. Identification by RP-HPLC-DAD, FTIR, TGA and FESEMEDAX of natural pigments prepared from Datisca cannabina L. Dyes Pigm. 2012; 94: 437-42.

Falzari K, Zhu Z, Pan D, Liu H, Hongmanee P, Franzblau SG. In vitro and in vivo activities of macrolide derivatives against Mycobacterium tuberculosis. Antimicrob Agents Chemother. 2005; 49: 1447-54.

Gunasekaran S, Sundaramoorthy S, Sathiavelu M, Arunachalam S. The genus Mussaenda: A phytopharmacological review. J Chem Pharm Res. 2015; 7: 1037-42.

Guo B, Wang Y, Sun X, Tang K. Bioactive natural products from endophytes: A review. Appl Biochem Microbiol. 2008; 44: $136-42$.

Jouda JB, Mawabo IK, Notedji A, Mbazoa CD, Nkenfou J, Nkenfou CN. Anti-mycobacterial activity of polyketides from Penicillium sp. endophyte isolated from Garcinia nobilis against Mycobacterium smegmatis. Int J Mycobacteriol. 2016; 5: 192-96.

Kanokmedhakul S, Kanokmedhakul K, Nasomjai P, Louangsysouphanh S, Soytong K, Isobe M. Antifungal azaphilones from the fungus Chaetomium cupreum CC3003. J Nat Prod. 2006; 69: 891-95.

Li X, Tian Y, Yang S, Zhang Y, Qin JC. Cytotoxic azaphilone alkaloids from Chaetomium globosum TY1. Bioorg Med Chem Lett. 2013; 23: 2945-47.

Lienhardt C, Raviglione M, Spigelman M, Hafner R, Jaramillo E, Hoelscher M. New drugs for the treatment of tuberculosis: Needs, challenges, promise and prospects for the future. J Infect Dis. 2012; 205: S241-49.

Nagy L, Mehner H, Christy AA, Sletten E, Edelmann FT, Andersen QM. Preparation and structural studies on organotin (IV) complexes with flavonoids. J Radioanal Nucl 
Chem. 1998; 227: 89-99.

Reichenbach H, Kleinig H. The pigments of Flexibacter elegans: Novel and chemo systematically useful compounds. Arch Microbiol. 1974; 101: 134-44.

Schulz B, Wanke U, Draeger S, Aust HJ. Endophytes from herbaceous plants and shrubs: Effectiveness of surface sterilization methods. Mycol Res. 1993; 97: 1447-50.

Shen X, Zheng D, Gao J, Hou C. Isolation and evaluation of endophytic fungi with antimicrobial ability from Phyllostachys edulis. Bangladesh J Pharmacol. 2012; 7: 249-57.

Shylaja G, Sathiavelu A. Cytotoxicity of endophytic fungus Chaetomium cupreum from the plant Mussaenda luteola against breast cancer cell line MCF-7. Bangladesh J Pharmacol. 2017; 12: $373-75$.

Stafsnes MH, Bruheim P. Pigmented marine heterotrophic bacteria: Occurrence, diversity, and characterization of pigmentation. In: Marine biomaterials: Characterization, isolation and applications. Kim SK (ed). 1st ed. Boca Raton, CRC Press, 2013, pp 117-48.

Strobel G, Daisy B, Castillo U. The biological promise of microbial endophytes and their natural products. Plant Pathol J. 2005; 4: 161-76.

Venil CK, Zakaria ZA, Usha R, Ahmad WA. Isolation and characterization of flexirubin type pigment from Chryseobacterium sp. UTM-3T, Biocat Agri Biotechnol. 2014; 3: 103-07.

Vidyalakshmi KS, Vasanthi HR, Rajamanickam GV. Ethno- botany, phytochemistry and pharmacology of Mussaenda Species (Rubiaceae), Ethnobot Leaflets. 2008; 12: 469-75.

Wong SP, Leong LP, Koh JHW. Anti-oxidant activities of aqueous extracts of selected plants. Food Chem. 2006; 99: 775 $-83$.

Yadav M, Yadav A, Yadav JP. In vitro anti-oxidant activity and total phenolic content of endophytic fungi isolated from Eugenia jambolana Lam. Asian Pac J Trop Med. 2014; 7: S25661.

Yu H, Zhang L, Li L, Zheng C, Guo L, Li W, Sun P, Qin L. Recent developments and future prospects of antimicrobial metabolites produced by endophytes. Microbiol Res. 2010; 165: 437-49.

Yu Y, Ma BJ, Liua JS, Yuea JY, Chen HP, Liang YM, Zhou ZY, Wang GK, Wang G. Two new alkaloid metabolites produced by endophytic fungus Stagonosporopsis colihominis isolated from Dendrobium huoshanense. Phytochem Lett. 2017; 19: 26670 .

Zhang H, Bai X, Wu B. Evaluation of antimicrobial activities of extracts of endophytic fungi from Artemisia апnиа. Bangladesh J Pharmacol. 2012; 7: 120-23.

Zhang H, Ruan C, Bai X. Isolation and antimicrobial effects of endophytic fungi from Edgeworthia chrysantha. Bangladesh J Pharmacol. 2015; 10: 529-32.

Zhang Q, Xiao J, Sun QQ, Qin JC, Pescitelli G, Gao JM. Characterization of cytochalasins from the endophytic Xylaria sp. and their biological functions. J Agric Food Chem. 2014; 62: 10962-69. 